\title{
Contribution of Xanthine Oxidase-Derived Oxygen Free Radicals to the Development of Carbon Tetrachloride- Induced Acute Liver Injury in Rats
}

\author{
Yoshiji Ohta, ${ }^{1, *}$ Mutsumi Kongo-Nishimura, ${ }^{2}$ Yoichiro Imai, ${ }^{3}$ and Teruaki Kishikawa ${ }^{2}$ \\ ${ }^{1}$ Department of Chemistry and ${ }^{2}$ Department of Pediatric Surgery, School of Medicine, Fujita Health University \\ ${ }^{3}$ Department of Clinical Chemistry, Fujita Health University College, Toyoake, Aichi 470-1192, Japan
}

Received 25 December, 2002 ; Accepted 3 March, 2003

\begin{abstract}
Summary We examined how oxygen free radicals derived from xanthine oxidase (XOD) contribute to the development of carbon tetrachloride $\left(\mathrm{CCl}_{4}\right)$-induced acute liver injury in rats. In rats treated with $\mathrm{CCl}_{4}(1 \mathrm{ml} / \mathrm{kg})$, liver injury appeared $3 \mathrm{~h}$ after the treatment and developed by $24 \mathrm{~h}$, judged from the serum levels of transaminases. Hepatic and serum XOD activities and serum uric acid concentration did not change $6 \mathrm{~h}$ after $\mathrm{CCl}_{4}$ treatment, but they all increased at $12 \mathrm{~h}$ and further increased at $24 \mathrm{~h}$. An increase in the concentration of thiobarbituric acid reactive substances (TBARS), an index of lipid peroxidation, and decreases in reduced glutathione concentration and $\mathrm{Cu}, \mathrm{Zn}$-superoxide dismutase (SOD) activity, but not Mn-SOD activity, were observed in the liver at $6 \mathrm{~h}$ after $\mathrm{CCl}_{4}$ treatment and these changes were further enhanced at $24 \mathrm{~h}$. When allopurinol $(50 \mathrm{mg} / \mathrm{kg})$, an XOD inhibitor, was administered to $\mathrm{CCl}_{4}$-treated rats $6 \mathrm{~h}$ after $\mathrm{CCl}_{4}$ treatment, liver injury progression was prevented with attenuation of increased hepatic and serum XOD activities, serum uric acid concentration, and hepatic TBARS concentration and decreased hepatic reduced glutathione concentration and $\mathrm{Cu}, \mathrm{Zn}-\mathrm{SOD}$ activity at $24 \mathrm{~h}$ after $\mathrm{CCl}_{4}$ treatment. These results indicate that XOD-derived oxygen free radicals contribute to the progression of $\mathrm{CCl}_{4}$-induced acute liver injury in rats both by stimulating hepatic lipid peroxidation and by disrupting hepatic antioxidant defense system.
\end{abstract}

Key Words: liver injury (rat), carbon tetrachloride, xanthine oxidase, oxygen free radicals, allopurinol

\section{Introduction}

Much attention has been focused on the role of oxygen free radicals such as superoxide anion $\left(\mathrm{O}_{2}^{-}\right)$, hydrogen peroxide $\left(\mathrm{H}_{2} \mathrm{O}_{2}\right)$, and hydroxyl radical in the pathogenesis of various types of liver injuries in humans and experimental animals $[1,2]$. Xanthine oxidase (XOD) generates large quantities of $\mathrm{O}_{2}{ }^{-}$and $\mathrm{H}_{2} \mathrm{O}_{2}$ in the presence of hypoxanthine or xanthine

\footnotetext{
* To whom correspondence should be addressed.

Tel: +81-562-93-2573 Fax: +81-562-93-4593/1193

E-mail: yohta@fujita-hu.ac.jp
}

$[3,4]$. It has been reported that XOD activity increases in the serum and liver of patients with liver diseases, especially acute viral hepatitis [5-10].

There are some reports showing that an increase in the hepatic level of lipid peroxide (LPO), which is produced via oxygen free radicals, and decreases in the hepatic level of reduced glutathione (GSH), which protects liver cells against oxidative damage due to oxygen free radicals and lipid peroxidation, and the hepatic activity of superoxide dismutase (SOD), an enzyme to scavenge $\mathrm{O}_{2}^{-}$, occurs with the formation of acute liver injury in rats treated once with carbon tetrachloride $\left(\mathrm{CCl}_{4}\right)$ and that these changes are enhanced with the progression of the 
injury [11-13]. $\mathrm{Cu}, \mathrm{Zn}$ - and $\mathrm{Mn}-\mathrm{SOD}$ s are present in the cytosol and mitochondria of rat liver cells, respectively [14]. Ito [15] has shown in rats treated once with $\mathrm{CCl}_{4}$ that a decrease in hepatic $\mathrm{Cu}, \mathrm{Zn}$ SOD activity, but not Mn-SOD activity, occurs with an increase in hepatic LPO level at an early stage of liver injury and that both changes are enhanced at a progressed stage of the injury. It has been reported that XOD activity increases in the serum and liver of rats with a single $\mathrm{CCl}_{4}$ treatment $[5,16-18]$. It has also been reported that an increase in the content of uric acid, an XOD-derived metabolite, occurs with both an increase in LPO level and a decrease in SOD activity in the damaged liver of rats treated once with $\mathrm{CCl}_{4}$ [19]. Allopurinol functions as an $\mathrm{XOD}$ inhibitor $[20,21]$. This drug is known to protect against $\mathrm{CCl}_{4}$-induced acute liver injury in rats $[22,23]$. However, there is a report showing that neither $\mathrm{Cu}, \mathrm{Zn}-\mathrm{SOD}$ activity nor $\mathrm{Mn}-\mathrm{SOD}$ activity changes in the damaged liver of rats treated once with $\mathrm{CCl}_{4}$, although increased LPO level and decreased GSH level are observed in the damaged liver [24]. Affonso et al. [18] have shown in rats with a single $\mathrm{CCl}_{4}$ treatment that the time course of serum XOD activity is very similar to that of hepatic XOD activity and that the enzyme activity reaches a peak around the same time point in the serum and liver. In contrast, Ramboer et al. [5] have shown in rats treated once with $\mathrm{CCl}_{4}$ that serum XOD activity begins to increase before the appearance of liver injury and reaches a peak at the time when the injury appears, while hepatic XOD activity begins to increase at the onset of acute liver injury and continues to increase during the injury development. Thus, it is still obscure how XOD-derived oxygen free radicals contribute to the development of $\mathrm{CCl}_{4}$-induced acute liver injury in rats.

We, therefore, attempted to clarify how XODderived oxygen free radicals contribute to the development of $\mathrm{CCl}_{4}$-induced acute liver injury in rats. Namely, we examined the relationship between the development of acute liver injury and the changes in the serum and hepatic activities of XOD and the serum concentration of uric acid in rats treated once with $\mathrm{CCl}_{4}$. We further examined the preventive effect of allopurinol on liver injury development and the changes in the serum and hepatic activities of $\mathrm{XOD}$, the serum concentration of uric acid, the hepatic concentrations of thiobarbituric acid reactive substances (TBARS), an index of lipid peroxidation, and $\mathrm{GSH}$, and the hepatic activities of $\mathrm{Cu}, \mathrm{Zn}$ - and
$\mathrm{Mn}-\mathrm{SOD}$ s with the injury development in $\mathrm{CCl}_{4}-$ treated rats.

\section{Materials and Methods}

\section{Chemicals}

Bovine erythrocyte $\mathrm{Cu}, \mathrm{Zn}-\mathrm{SOD}$, bovine serum albumin, leupeptin, and xanthine were obtained from Sigma Chemical Co. (St. Louis, MO, USA); bovine milk XOD, horseradish peroxidase, 2,2'-azino-di-(3-ethylbenzthiazoline-6-sulfonate) (ABTS), dithiothreitol, GSH, and phenylmethylsulfonylfluoride from Roche-Diagnotics Co. (Tokyo, Japan); yeast uricase from Oriental Yeast Co. (Tokyo, Japan); allopurinol, $\mathrm{CCl}_{4}, 5,5^{\prime}$-dithiobis(2-nitrobenzoic acid) (Ellman's reagent), ethylenediaminetetraacetic acid (EDTA), hypoxanthine, olive oil, 2-thiobarbituric acid, and other reagents from Wako Pure Chemicals Ind., Ltd. (Osaka, Japan). These reagents were used without further purification.

\section{Animals}

Male Wistar rats (5 weeks old) were purchased from Nippon SLC Co. (Hamamatsu, Japan) and fed commercial rat chow, Oriental MF (Oriental Yeast Co., Tokyo, Japan) with free access to water for 1 week before use for the experiments. All animals received humane care in compliance with the guidelines of the Animal Care and Use Committee of Fujita Health University.

\section{Induction of liver injury}

$\mathrm{CCl}_{4}$ was diluted by 2 -fold with olive oil. One milliliter per $\mathrm{kg}$ body weight (B.W.) of $\mathrm{CCl}_{4}$, that is, $2 \mathrm{ml} / \mathrm{kg} \mathrm{B}$.W. of this $50 \% \mathrm{CCl}_{4}$ solution, was intraperitoneally injected to fed rats (6 weeks old) to produce liver injury. Rats without $\mathrm{CCl}_{4}$ injection received an intraperitoneal (i.p.) injection of an equal volume of olive oil. These animals were starved with free access to water after $\mathrm{CCl}_{4}$ injection, as described in the report of Villela and Mitidieri [16].

\section{Allopurinol treatment}

A solution of allopurinol $(10 \mathrm{mg} / \mathrm{ml})$ was prepared as follows: $10 \mathrm{mg}$ of allopurinol was dissolved in a limited volume of $1 \mathrm{M} \mathrm{NaOH}, \mathrm{pH}$-adjusted to 10.9 with $1 \mathrm{M} \mathrm{HCl}$, and then diluted with distilled water in a final volume of $1.0 \mathrm{ml}$. The allopurinol solution at a dose of $50 \mathrm{mg} / \mathrm{kg}$ B.W. was orally administered to rats injected with and without $\mathrm{CCl}_{4}$ at $6 \mathrm{~h}$ after hepatotoxin injection using a stomach tube. This 
dose of allopurinol was determined according to the report of Klein et al. [21] which indicates that orally administered allopurinol inhibits XOD activity in the liver of rats without exerting an antioxidant effect at doses of $2-50 \mathrm{mg} / \mathrm{kg}$ B.W. An equal volume of a diluted $\mathrm{NaOH}$ solution $(\mathrm{pH} 10.9)$ prepared without allopurinol was orally administered to rats without allopurinol administration at the same time point.

\section{Sample preparations}

Rats were sacrificed after collecting blood from the vena cava caudalis under ether anesthesia at $3,6,12$, and $24 \mathrm{~h}$ after $\mathrm{CCl}_{4}$ injection. Immediately after sacrifice, livers were perfused with ice-cold $0.15 \mathrm{M} \mathrm{KCl}$ through the portal vein to remove residual blood in the tissue as much as possible and then removed from the body. The isolated liver was washed well in ice-cold $0.15 \mathrm{M} \mathrm{KCl}$, clotted on a filter, weighed, and frozen on dry ice as soon as possible. The collected blood was kept on ice for $30 \mathrm{~min}$ and then separated into serum by centrifugation at $4{ }^{\circ} \mathrm{C}$. The isolated liver and serum were kept at $-80^{\circ} \mathrm{C}$ until use. For liver $\mathrm{XOD}$ assay, a part of the right large lobe of each liver was homogenized in 9 volumes of an ice-cold buffered solution ( $\mathrm{pH} 7.8$ ) containing $0.05 \mathrm{M}$ potassium phosphate, $0.1 \mathrm{M}$ EDTA, $0.5 \mathrm{mM}$ dithiothreitol, 0.5 $\mathrm{mg} / \mathrm{ml}$ leupeptin, and $0.2 \mathrm{mM}$ phenylmethylsulfonylfluoride using a glass homogenizer with a Telfon pestle as described by Engerson et al. [25]. The homogenate was dialyzed against 100 volumes of the same buffered solution at $4^{\circ} \mathrm{C}$ for $60 \mathrm{~min}$ using a microdialysis device (Molecular cut-off $=3,500 \mathrm{Da}$ ) (Bio-Tec International Inc., Belleuve, WA, USA). For determinations of hepatic LPO, GSH, and SOD activity, another part of the right large lobe of each liver was homogenized in 9 volumes of ice-cold $0.15 \mathrm{M} \mathrm{KCl}$ containing $1.0 \mathrm{mM}$ EDTA using a glass homogenizer with a Telfon pestle. For hepatic and serum SOD assays, the liver homogenate or serum was dialyzed against 100 volumes of $0.05 \mathrm{M}$ Tris$\mathrm{HCl}$ buffer $\left(\mathrm{pH} \mathrm{7.4)}\right.$ at $4^{\circ} \mathrm{C}$ for 60 min using the above-described microdialysis device.

\section{Determinations of aminotransferases and XOD activi- ties and uric acid in serum}

Serum alanine aminotransferase (ALT) and aspartate aminotransferase (AST) activities were assayed using a commercial kit, Iatorzyme TA-L $\mathrm{L}_{\mathrm{Q}}$ (DaiIatron Co., Tokyo, Japan). Both activities are expressed as an international unit (IU/liter). Serum
$\mathrm{XOD}$ activity was assayed at $30^{\circ} \mathrm{C}$ by the method of Majkic-Singh et al. [26] using hypoxanthine as a substrate. This assay method is based on the peroxidasemediated oxidation of ABTS by $\mathrm{H}_{2} \mathrm{O}_{2}$ produced in the metabolism of uric acid, a product of the XODcatalyzed oxidation of xanthine, to allantoin by exogenously added uricase. One unit (U) of serum XOD is defined as the amount of enzyme forming $1 \mu \mathrm{mol}$ uric acid per min at $30^{\circ} \mathrm{C}$. Serum uric acid was determined using a commercial kit, Uric Acid C-Test Wako (Wako Pure Chemicals Ind., Ltd.)

Determinations of XOD and SOD activities and TBARS, GSH, and protein in liver

Hepatic XOD activity was assayed at $30^{\circ} \mathrm{C}$ by the method of Hashimoto [27] using xanthine as a substrate. This enzyme activity was assessed by measuring the increase in absorbance at $292 \mathrm{~nm}$ following the formation of uric acid. One unit (U) of liver $\mathrm{XOD}$ is defined as the amount of enzyme forming 1 $\mu \mathrm{mol}$ uric acid per min. Hepatic $\mathrm{Cu}, \mathrm{Zn}-$ and $\mathrm{Mn}-$ SOD activities were assayed at $37^{\circ} \mathrm{C}$ by the nitrateXOD method of Oyanagui [28]. $\mathrm{Cu}, \mathrm{Zn}-$ and $\mathrm{Mn}-$ SOD activities were measured as follows: total SOD activity was measured in the absence of $1 \mathrm{mM} \mathrm{KCN}$, which inhibits the activity of $\mathrm{Cu}, \mathrm{Zn}-\mathrm{SOD}$ [28]. $\mathrm{Mn}-\mathrm{SOD}$ activity was measured in the presence of $1 \mathrm{mM} \mathrm{KCN}$. Cu,Zn-SOD activity was estimated from the difference between the total SOD and $\mathrm{Mn}$ SOD activities. The activity of $\mathrm{Cu}, \mathrm{Zn}$ - or $\mathrm{Mn}-\mathrm{SOD}$ is expressed as the amount of bovine erythrocyte SOD showing activity equivalent to the activity determined in the $\mathrm{O}_{2}{ }^{-}$-generating system of xanthine and bovine milk XOD. Hepatic TBARS was determined by the method of Ohkawa et al. [29] using the thiobarbituric acid reaction except that $1.0 \mathrm{mM}$ EDTA was added to the reaction mixture. The concentration of TBARS is expressed as the amount of malondialdehyde (MDA) equivalents. Hepatic GSH was determined by the method of Sedlak and Lindsay [30] using Ellman's reagent and GSH as a standard. Hepatic protein was determined by the method of Lowry et al. [31] using bovine serum albumin as a standard.

\section{Statistical analysis}

Results obtained are expressed as means \pm S.D. Results were statistically analyzed by computerized statistical packages (ANOVA, StatView). Each mean value was compared by one-way analysis of variance and Fisher's protected significant difference 

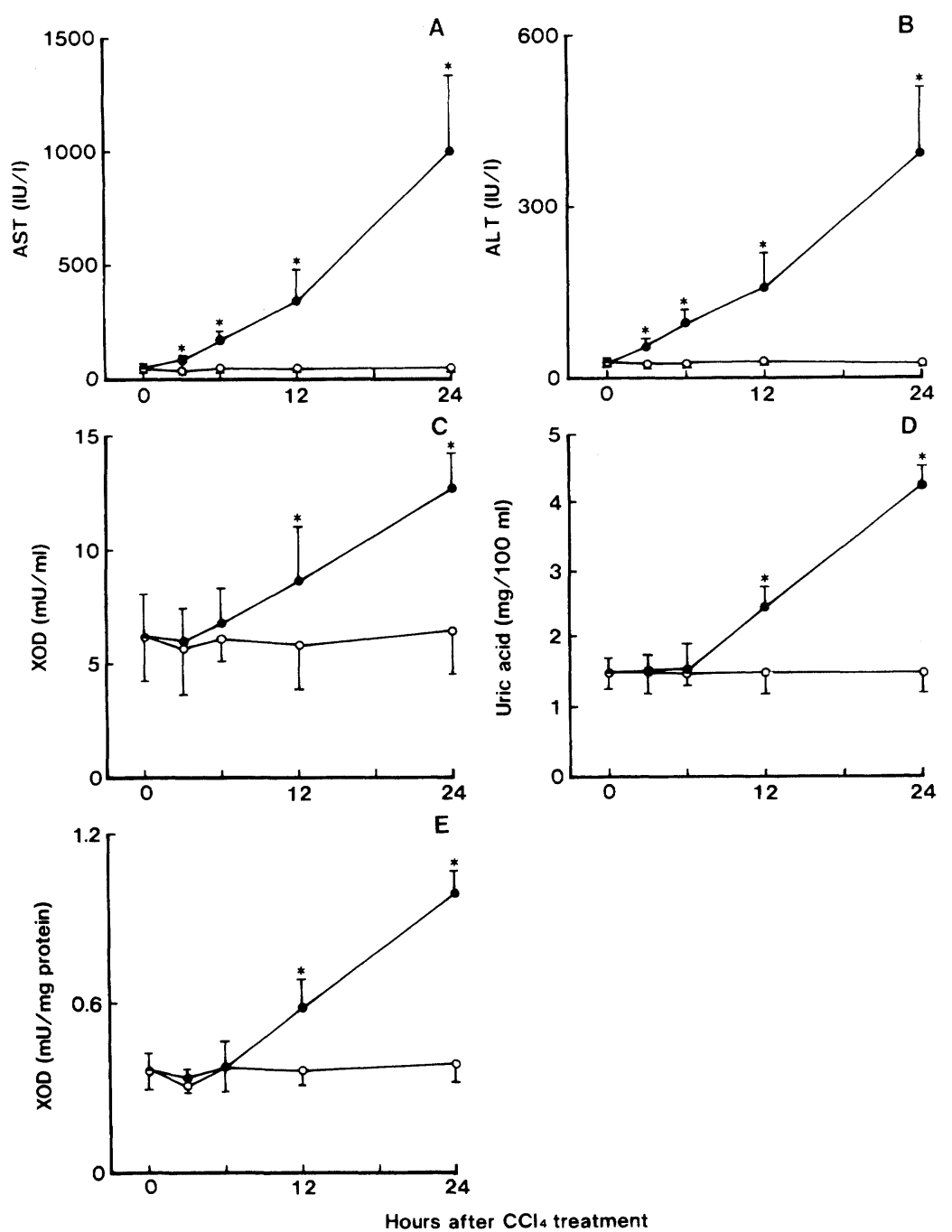

Fig. 1. Changes in serum AST (A), ALT (B), and XOD (C) activities, uric acid concentration (D) and hepatic XOD activity (E) in rats following $\mathrm{CCl}_{4}$ treatment. Rats with and without a single i.p. injection of $\mathrm{CCl}_{4}(1 \mathrm{ml} / \mathrm{kg} \mathrm{B} . \mathrm{W}$.) were sacrificed 3, 6, 12, and $24 \mathrm{~h}$ after hepatotoxin treatment. Serum AST, ALT, and XOD activities and uric acid, and hepatic XOD activity were assayed in both groups as described in Materials and Methods. Open circle, control rats; closed circle, $\mathrm{CCl}_{4}$-treated rats. Each value is a mean $\pm \mathrm{SD}(n=5-10) .{ }^{*} p<0.05$ (vs. control rats).

for multicomparison as the post hoc test. The level of significance was taken as $p<0.05$.

\section{Results}

Changes in serum AST, ALT, and XOD activities and uric acid concentration and hepatic $X O D$ activity in rats following $\mathrm{CCl}_{4}$ treatment

AST and ALT activities in the serum of rats treated with $\mathrm{CCl}_{4}(1 \mathrm{ml} / \mathrm{kg}$ B.W. $)$ began to increase $3 \mathrm{~h}$ after the treatment and continued to increase until $24 \mathrm{~h}$; the AST and ALT activities in the treated group were 20.8- and 16.4-fold, respectively, higher than those in the control group without $\mathrm{CCl}_{4}$ treatment at $24 \mathrm{~h}$ after the treatment (Fig. $1 \mathrm{~A}$ and B). $\mathrm{XOD}$ activity and uric concentration in the serum of the $\mathrm{CCl}_{4}$-treated group increased later than $6 \mathrm{~h}$ after the treatment and continued to increase until $24 \mathrm{~h}$; the XOD activity and uric acid concentration in the treated group were 2.0- and 2.8-fold, respectively, higher than those in the control group at $24 \mathrm{~h}$ after the treatment (Fig. $1 \mathrm{C}$ and D). XOD activity in the liver of the $\mathrm{CCl}_{4}$-treated group increased later than 6 $\mathrm{h}$ after the treatment and continued to increase until $24 \mathrm{~h}$; the treated group had a 2.6-fold higher hepatic XOD activity than the control group (Fig. 1E). 


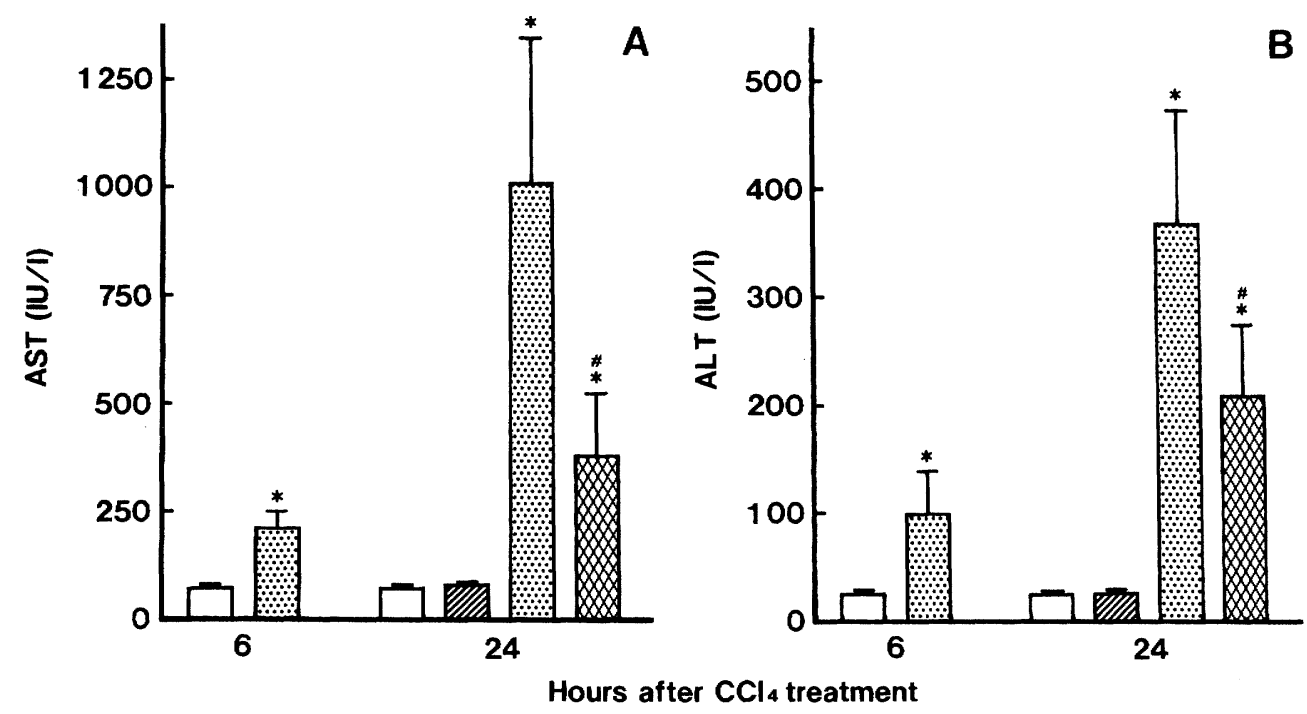

Fig. 2. Effect of post-allopurinol administration on serum AST (A) and ALT (B) activities in $\mathrm{CCl}_{4}$-treated rats. Rats received a single i.p. injection of either $\mathrm{CCl}_{4}\left(1 \mathrm{ml} / \mathrm{kg} \mathrm{B.W}\right.$.) or olive oil. At $6 \mathrm{~h}$ after $\mathrm{CCl}_{4}$ treatment, they received a single oral administration of either allopurinol $(50 \mathrm{mg} / \mathrm{kg} \mathrm{B.W.)} \mathrm{or} \mathrm{a} \mathrm{diluted} \mathrm{NaOH}$ solution ( $\mathrm{pH} 10.9)$ used as a vehicle. The animals were sacrificed 6 or $24 \mathrm{~h}$ after $\mathrm{CCl}_{4}$ treatment. Serum AST and ALT activities were assayed in each group as described in Materials and Methods. Open bar, control rats: dotted bar, rats treated with $\mathrm{CCl}_{4}$ alone; hatched bar, rats administered with allopurinol alone; crosshatched bar, $\mathrm{CCl}_{4}$-treated rats with allopurinol administration. Each value is a mean $\pm \mathrm{SD}(n=7-10)$. ${ }^{*} p<0.05$ (vs. control rats); ${ }^{\#} p<0.05$ (vs. corresponding rats treated with $\mathrm{CCl}_{4}$ alone).

Effect of post-allopurinol administration on serum AST and $A L T$ activities in $\mathrm{CCl}_{4}$-treated rats

In rats treated with $\mathrm{CCl}_{4}(1 \mathrm{ml} / \mathrm{kg}$ B.W. $)$, serum AST and ALT activities significantly increased $6 \mathrm{~h}$ after toxicant treatment and further increases in both activities occurred at $24 \mathrm{~h}$; the AST and ALT activities in the treated group were 14.7- and 14.8-fold, respectively, higher than those in the control group at $24 \mathrm{~h}$ after hepatotoxin treatment (Fig. 2). When allopurinol $(50 \mathrm{mg} / \mathrm{kg}$ B.W. $)$ was orally administered to $\mathrm{CCl}_{4}$-treated rats at $6 \mathrm{~h}$ after hepatotoxin treatment, increases in serum AST and ALT activities found at $24 \mathrm{~h}$ after hepatotoxin treatment were significantly depressed; the AST and ALT activities in the $\mathrm{CCl}_{4}$-treated group with post-allopurinol administration were 5.6- and 8.4-fold, respectively, higher than those in the control group (Fig. 2). This allopurinol administration had no effect on serum AST and ALT activities in $\mathrm{CCl}_{4}$-untreated rats (Fig. 2).

\section{Effect of post-allopurinol administration on serum XOD} activity and uric acid concentration in $\mathrm{CCl}_{4}$-treated rats

At $6 \mathrm{~h}$ after $\mathrm{CCl}_{4}$ treatment, there were no differences in serum XOD activity and uric acid concentration between the $\mathrm{CCl}_{4}$-treated and control groups (Fig. 3). At $24 \mathrm{~h}$ after $\mathrm{CCl}_{4}$ treatment, serum XOD activity and uric acid concentration in the treated group were 1.6- and 2.5-fold, respectively, higher than those in the control group (Fig. 3). Both increases in $\mathrm{CCl}_{4}$-treated rats were significantly attenuated by post-oral administration of allopurinol; serum XOD activity and uric acid concentration in the $\mathrm{CCl}_{4}$-treated group with post-allopurinol administration were almost equal to those in the control group (Fig. 3). Serum XOD activity and uric acid concentration in $\mathrm{CCl}_{4}$-untreated rats given allopurinol were 47.1 and $36.4 \%$, respectively, of those in control rats (Fig. 3).

\section{Effect of post-allopurinol administration on hepatic $\mathrm{XOD}$ activity in $\mathrm{CCl}_{4}$-treated rats}

At $6 \mathrm{~h}$ after $\mathrm{CCl}_{4}$ treatment, there was no difference in hepatic XOD activity between the $\mathrm{CCl}_{4}-$ treated and control rats (Fig. 4). At $24 \mathrm{~h}$ after $\mathrm{CCl}_{4}$ treatment, hepatic $\mathrm{XOD}$ activity in the $\mathrm{CCl}_{4}$-treated group was 3.3-fold higher than that in the control group (Fig. 4). This increase in hepatic XOD activity was significantly attenuated by post-oral administration of allopurinol; the XOD activity in the treated group with post-allopurinol administration was 2.0fold higher than that in the control group (Fig. 4). Hepatic XOD activity in $\mathrm{CCl}_{4}$-untreated rats given 


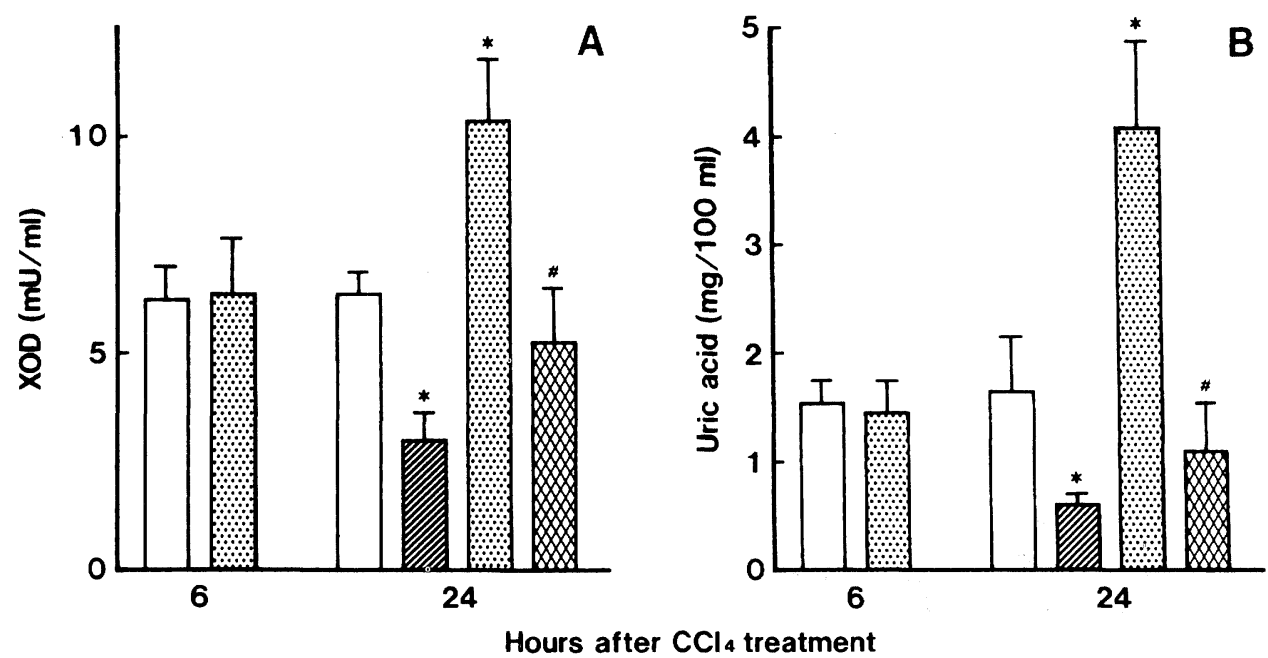

Fig. 3. Effect of post-allopurinol administration on serum XOD activity (A) and uric acid concentration (B) in $\mathrm{CCl}_{4}{ }^{-}$ treated rats. Experimental conditions and explanation are the same as described in the legend for Fig. 2 except that serum XOD activity and uric acid were assayed in each group as described in Materials.

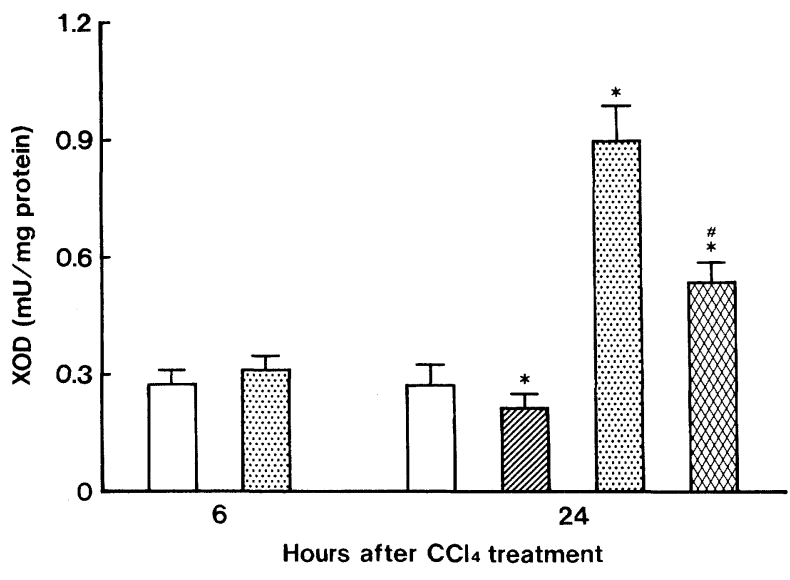

Fig. 4. Effect of post-allopurinol administration on hepatic XOD activity in $\mathrm{CCl}_{4}$-treated rats. Experimental conditions and explanation are the same as described in the legend for Fig. 2 except that hepatic XOD activity was assayed in each group as described in Materials.

allopurinol was significantly lower than that in control rats (Fig. 4).

Effect of post-allopurinol administration on hepatic TBARS and $\mathrm{GSH}$ concentrations in $\mathrm{CCl}_{4}$-treated rats

At $6 \mathrm{~h}$ after $\mathrm{CCl}_{4}$ treatment, hepatic TBARS concentration in the $\mathrm{CCl}_{4}$-treated group was significantly higher than that in the control group, whereas hepatic $\mathrm{GSH}$ concentration in the $\mathrm{CCl}_{4}$-treated group was significantly lower than that in the control group (Fig. 5). At $24 \mathrm{~h}$ after $\mathrm{CCl}_{4}$ treatment, a further increase in hepatic TBARS concentration and a further decrease in hepatic GSH concentration occurred in the $\mathrm{CCl}_{4}$-treated group; the TBARS concentration in the treated group was 1.7-fold higher than that in the control group, while the GSH concentration in the treated group was $65 \%$ of that in the control group (Fig. 5). Both the increase in hepatic TBARS concentration and the decrease in hepatic GSH concentration found at $24 \mathrm{~h}$ after $\mathrm{CCl}_{4}$ treatment were significantly attenuated by post-oral administration of allopurinol; the TBARS concentration in the $\mathrm{CCl}_{4}$-treated group with post-allopurinol administration were 1.3 -fold more than that in that control group, while the GSH concentration in the $\mathrm{CCl}_{4}$-treated group with post-allopurinol administration was $85 \%$ of that in the control group (Fig. 5). Hepatic TBARS and GSH concentrations in $\mathrm{CCl}_{4}$-untreated rats given allopurinol were not different from those in control rats (Fig. 5).

\section{Effect of post-allopurinol administration on hepatic $S O D$ activity in $\mathrm{CCl}_{4}$-treated rats}

Hepatic $\mathrm{Cu}, \mathrm{Zn}$-SOD activity in the $\mathrm{CCl}_{4}$-treated group was significantly lower than that in the control group at 6 and $24 \mathrm{~h}$ after the treatment; the SOD activity in the treated group was $55 \%$ of that in the control group at $24 \mathrm{~h}$ (Fig. 6A). The decrease in hepatic $\mathrm{Cu}, \mathrm{Zn}-\mathrm{SOD}$ activity found at $24 \mathrm{~h}$ after $\mathrm{CCl}_{4}$ treatment was significantly suppressed by postoral administration of allopurinol; the $\mathrm{Cu}, \mathrm{Zn}$-SOD activity in the $\mathrm{CCl}_{4}$-treated group with post-allopurinol administration was near the control level (Fig. 6A). There was no difference in hepatic Mn-SOD 


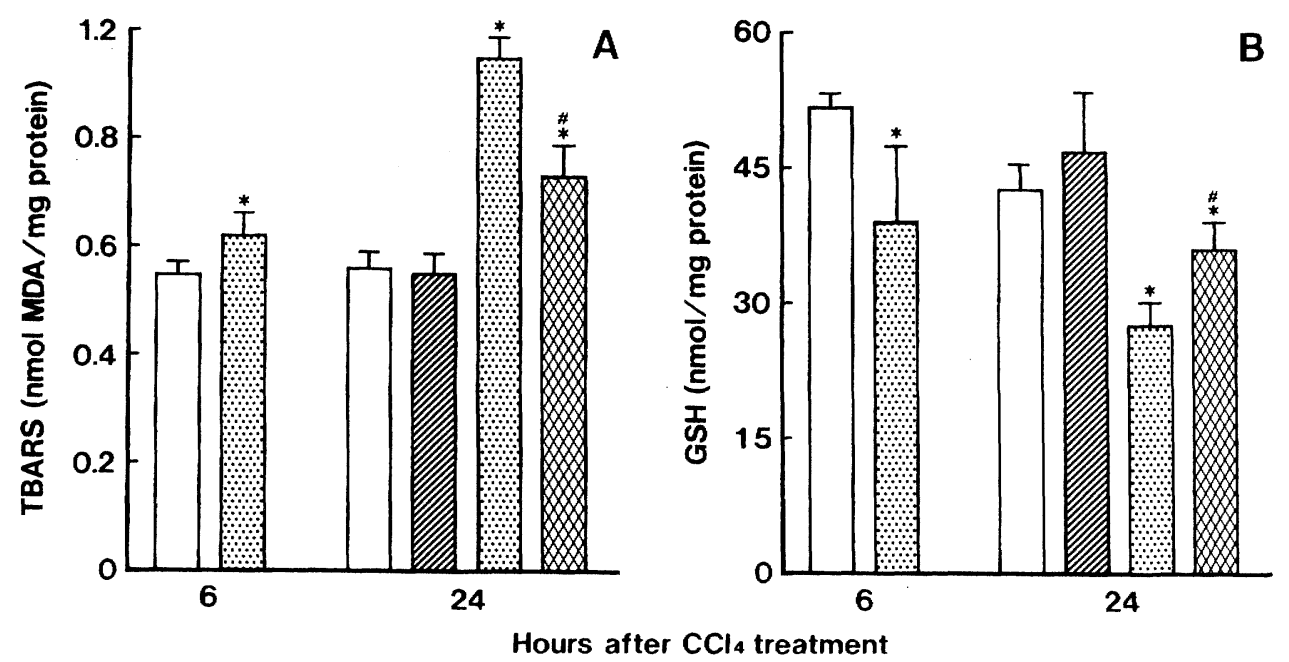

Fig. 5. Effect of post-allopurinol administration on hepatic TBARS (A) and GSH (B) concentrations in $\mathrm{CCl}_{4}$-treated rats. Experimental conditions and explanation are the same as described in the legend for Fig. 2 except that hepatic TBARS and GSH were assayed in each group as described in Materials.

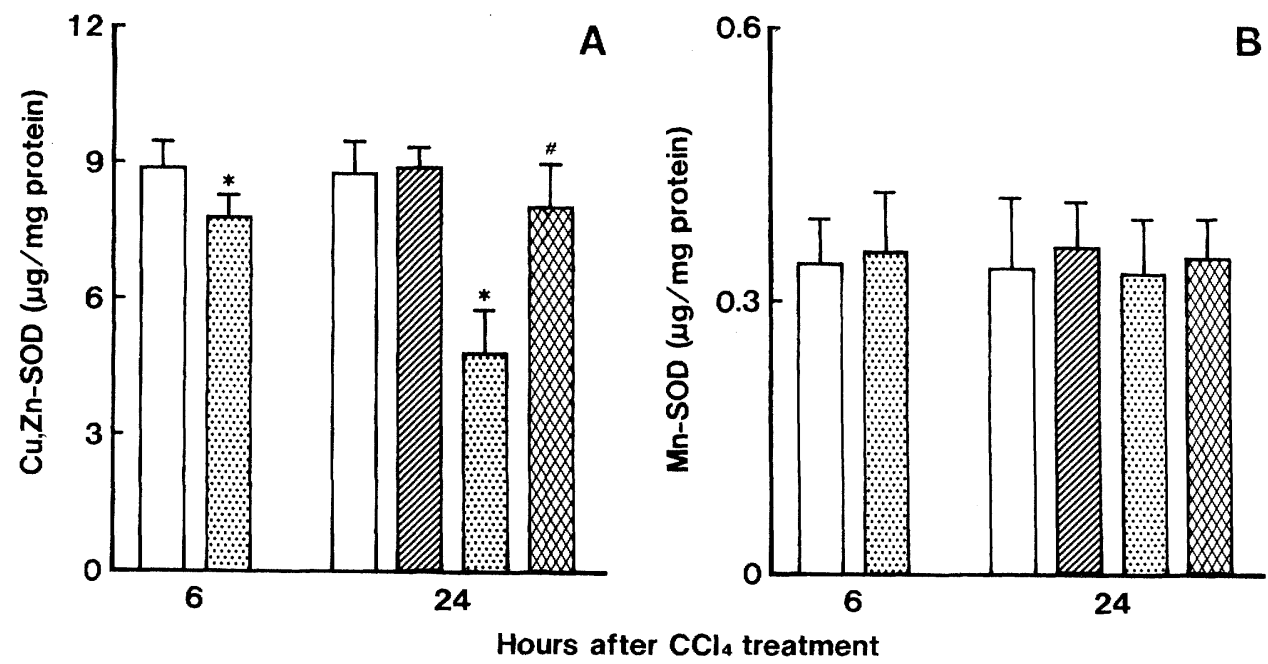

Fig. 6. Effect of post-allopurinol administration on hepatic $\mathrm{Cu}, \mathrm{Zn}-\mathrm{SOD}(\mathrm{A})$ and $\mathrm{Mn}-\mathrm{SOD}(\mathrm{B})$ activities in $\mathrm{CCl}_{4}$-treated rats. Experimental conditions and explanation are the same as described in the legend for Fig. 2 except that hepatic $\mathrm{Cu}, \mathrm{Zn}-\mathrm{SOD}$ and $\mathrm{Mn}-\mathrm{SOD}$ activities were assayed in each group as described in Materials.

activity between the $\mathrm{CCl}_{4}$-treated and control groups at 6 and $24 \mathrm{~h}$ after $\mathrm{CCl}_{4}$ treatment and post-oral administration of allopurinol did not affect the hepatic Mn-SOD activity at $24 \mathrm{~h}$ after the treatment (Fig. 6B). Oral administration of allopurinol to $\mathrm{CCl}_{4}$-untreated rats had no effect on $\mathrm{Cu}, \mathrm{Zn}$ - and $\mathrm{Mn}$-SOD activities in the liver (Fig. 6).

\section{Discussion}

$\mathrm{CCl}_{4}$ is long known to cause hepatic centrilobular necrosis, although a recent report indicates that the hepatotoxin induces not only necrosis but also apop- tosis in the liver of rats [32]. The hepatotoxicity of $\mathrm{CCl}_{4}$ requires the hepatic cytochrome $\mathrm{P} 450$-mediated metabolism of $\mathrm{CCl}_{4}$ to trichloromethyl radical $\left({ }^{\circ} \mathrm{CCl}_{3}\right)$ and involves the formation of free radicals such as ${ }^{\circ} \mathrm{CCl}_{3}$ and its $\mathrm{O}_{2}$ adduct $\left({ }^{\circ} \mathrm{CCl}_{3} \mathrm{OO}\right)$ and lipid peroxidation initiated by $\mathrm{CCl}_{4}$-derived free radicals [33].

In the present study, rats with a single i.p. injection of $\mathrm{CCl}_{4}(1 \mathrm{ml} / \mathrm{kg}$ B.W. $)$ showed liver injury, which was judged from serum AST and ALT activities, indices of liver cell damage, at least $3 \mathrm{~h}$ before the observation of significant increases in serum and hepatic XOD activities and serum uric acid concen- 
tration. The serum and hepatic XOD activities in the $\mathrm{CCl}_{4}$-treated rats began to increase later than $6 \mathrm{~h}$ after hepatotoxin treatment and continued to increase until $24 \mathrm{~h}$. Thus, serum and hepatic XOD activities were found to increase with an increase in serum uric acid concentration after the formation of liver injury in rats treated once with $\mathrm{CCl}_{4}$. These results may allow us to postulate that $\mathrm{XOD}$-derived oxygen radicals contribute to the progression, but not the formation, of $\mathrm{CCl}_{4}$-induced liver injury in rats. The relation between the time-dependent changes of serum and hepatic XOD activities in $\mathrm{CCl}_{4}$-treated rats observed in the present study was similar to that reported by Affonso et al. [18], but not that reported by Ramboer et al. [5].

The mechanism for the increases in serum and hepatic XOD activities in rats treated once with $\mathrm{CCl}_{4}$ is poorly understood. Villela and Mitidieri [16] have shown that hepatic XOD in rats treated with $\mathrm{CCl}_{4}$ is activated by the oxidation of the substrate present in the liver tissue, while hepatic xanthine dehydrogenase $(\mathrm{XDH})$ is inactivated. Several reports have demonstrated that hepatic microcirculation disturbance, which produces hypoxia or ischemia in liver tissues, occurs during the progression of $\mathrm{CCl}_{4}$ induced acute liver injury in rats, and have suggested that this hepatic microcirculation disturbance is associated mainly with the progression of $\mathrm{CCl}_{4}$-induced acute liver injury [34-39]. Engerson et al. [25] have shown that $\mathrm{XDH}$ converts to $\mathrm{XOD}$ in ischemic rat liver by a proteolytic mechanism. Hamer et al. [40] have also shown that $\mathrm{XDH}$ converts to XOD in ischemic rat livers in vivo and that a marked increase in XOD activity occurs in parallel with a decrease in cell viability in isolated rat liver cells with ischemia in vitro. In addition, plasma XOD activity increases in rats with ischemic livers [41]. Uric acid is released from perfused rat livers subjected to hypoxia or ischemia [42, 43]. The levels of XOD-derived metabolites, xanthine plus uric acid, are elevated during ischemia in the liver of rats [44]. In the present study, serum and hepatic XOD activities and serum uric acid concentration increased with the progression of liver injury in rats treated once with $\mathrm{CCl}_{4}$. These findings may allow us to think that ischemia or hypoxia induced by hepatic microcirculation disturbance contributes to the conversion of $\mathrm{XDH}$ to $\mathrm{XOD}$ in the liver of rats treated once with $\mathrm{CCl}_{4}$, resulting in increases in serum and hepatic $\mathrm{XOD}$ activities, which is associated with the progression of $\mathrm{CCl}_{4}$-induced acute liver injury.
We further attempted to certify the contribution of XOD-derived oxygen free radicals to the progression of $\mathrm{CCl}_{4}$-induced acute liver injury using $\mathrm{CCl}_{4}$ treated rats with post-administration of allopurinol, an XOD inhibitor [20, 21]. Allopurinol $(50 \mathrm{mg} / \mathrm{kg}$ B.W.) was orally administered to rats treated with $\mathrm{CCl}_{4}$ at $6 \mathrm{~h}$ after hepatotoxin treatment at which time liver injury had already developed. This postadministration of allopurinol prevented the progression of liver injury with inhibition of the increases in serum and hepatic XOD activities and serum uric acid concentration with the injury progression. In addition, an inhibitory effect of orally administered allopurinol on $\mathrm{XOD}$ activity was observed in the serum and liver of $\mathrm{CCl}_{4}$-untreated rats. These results suggest that $\mathrm{XOD}$-derived oxygen radicals contribute to the progression of $\mathrm{CCl}_{4}$-induced acute liver injury in rats. Horváth et al. [23] have demonstrated that when allopurinol $(50 \mathrm{mg} / \mathrm{kg}$ B.W. $)$ in combination with $\mathrm{CCl}_{4}$ is orally administered to rats, the drug protects the liver from $\mathrm{CCl}_{4}$-induced acute injury possibly by inhibiting the cytochrome $\mathrm{P} 450$ mediated activation of $\mathrm{CCl}_{4}$ to ${ }^{\circ} \mathrm{CCl}_{3}$ in the liver tissue. It is known that the cytochrome $\mathrm{P} 450$-mediated activation of $\mathrm{CCl}_{4}$ to ${ }^{\circ} \mathrm{CCl}_{3}$ and ${ }^{\cdot} \mathrm{CCl}_{3} \mathrm{OO}$ terminates in the liver of rats treated once with $\mathrm{CCl}_{4}(5 \mathrm{ml} / \mathrm{kg}$ B.W., i.p.) within a few hours after the hepatotoxin is given [45]. Accordingly, it can be thought that pretreated allopurinol prevents $\mathrm{CCl}_{4}$-induced liver injury in rats at $6 \mathrm{~h}$ after hepatotoxin treatment without inhibiting XOD. Furthermore, it seems unlikely that allopurinol administered to $\mathrm{CCl}_{4}$-treated rats at $6 \mathrm{~h}$ after hepatotoxin treatment affects the cytochrome $\mathrm{P} 450$-mediated activation of $\mathrm{CCl}_{4}$ to $\cdot \mathrm{CCl}_{3}$ and ${ }^{\circ} \mathrm{CCl}_{3} \mathrm{OO}$ in the liver tissue.

In the present study, both an increase in the hepatic concentration of TBARS, an index of lipid peroxidation, and a decrease in the hepatic concentration of GSH, which is known to interact with oxygen free radicals generated by XOD-catalyzed metabolism of xanthine [46], found at an early stage of liver injury were enhanced at a progressed stage of the injury in rats treated with $\mathrm{CCl}_{4}$, as shown in previous reports [11-13]. The source of oxygen free radicals associated with increased hepatic TBARS level found at an early stage of $\mathrm{CCl}_{4}$-induced acute liver injury seems to be Kupffer cells, the resident macrophages of the liver, because there are reports showing that Kupffer cells producing oxygen free radicals are involved in an early process of $\mathrm{CCl}_{4}$-induced hepatotoxicity in rats [47] and that inhibition of Kupffer cells prevents 
hepatic lipid peroxidation and liver damage induced by $\mathrm{CCl}_{4}$ in rats [48]. Both enhancements of increased hepatic TBARS concentration and decreased hepatic GSH concentration with liver injury progression in $\mathrm{CCl}_{4}$-treated rats were significantly attenuated by allopurinol administered orally at an early stage of $\mathrm{CCl}_{4}$-induced liver injury. However, the same dose of allopurinol did not affect hepatic TBARS and GSH concentrations in $\mathrm{CCl}_{4}$-untreated rats. These results suggest that oxygen free radicals produced by XOD increasing in the liver of $\mathrm{CCl}_{4}$ treated rats cause the enhancements of increase in TBARS concentration and decrease in GSH concentration in the liver, which contributes to the progression of $\mathrm{CCl}_{4}$-induced acute liver injury. It has been shown in vitro that allopurinol and its main in vivo metabolite, oxypurinol, function as a scavenger of oxygen free radicals $[49,50]$. However, Klein et al. [21] have reported that while orally administered allopurinol at doses of $2-50 \mathrm{mg} / \mathrm{kg}$ B.W. effectively suppresses XOD activity in the liver of rats, antioxidant activity is not seen even in its doses up to $100 \mathrm{mg} / \mathrm{kg}$ B.W. Accordingly, it can be thought that XOD-derived oxygen free radicals contribute to the progression of $\mathrm{CCl}_{4}$-induced acute liver injury in rats by stimulating lipid peroxidation and GSH loss in the liver tissue.

In the present study, a decrease in hepatic $\mathrm{Cu}, \mathrm{Zn}$ SOD activity, but not $\mathrm{Mn}$-SOD activity, occurred at an early stage of $\mathrm{CCl}_{4}$-induced acute liver injury in rats and this decrease in $\mathrm{Cu}, \mathrm{Zn}-\mathrm{SOD}$ activity was enhanced at a progressed stage of the injury. These results were well consistent with those reported by Ito [15]. Oral administration of allopurinol to $\mathrm{CCl}_{4}$ treated rats at an early stage of liver injury significantly suppressed the decrease in hepatic $\mathrm{Cu}, \mathrm{Zn}$ SOD activity found at a progressed stage of the injury, although the allopurinol administration had no effect on hepatic Mn-SOD activity. These results allow us to think that, in rats treated once with $\mathrm{CCl}_{4}$, the reduced ability of $\mathrm{Cu}, \mathrm{Zn}-\mathrm{SOD}$ to scavenge $\mathrm{O}_{2}{ }^{-}$ generated via XOD increasing in the liver tissue contributes to the progression of liver injury. It is known that $\mathrm{Cu}, \mathrm{Zn}-\mathrm{SOD}$ is inactivated by $\mathrm{H}_{2} \mathrm{O}_{2}$ in vitro [51]. We have shown under the same experimental condition as used in the present study that the hepatic activity of catalase, an $\mathrm{H}_{2} \mathrm{O}_{2}$-metabolizing enzyme, decreases by approximately $25 \%$ at a progressed stage of acute liver injury in rats treated once with $\mathrm{CCl}_{4}(1 \mathrm{ml} / \mathrm{kg}$ B.W., i.p.) [12]. Accordingly, it is conceivable that, in rats treated once with
$\mathrm{CCl}_{4}, \mathrm{H}_{2} \mathrm{O}_{2}$ generated via XOD increasing in the liver tissue contributes to inactivation of $\mathrm{Cu}, \mathrm{Zn}$ $\mathrm{SOD}$ in the liver tissue, resulting in the reduced capacity to scavenge $\mathrm{O}_{2}{ }^{-}$in the liver tissue. Recently, Kang et al. [52] have shown in vitro that peroxyl radicals, which induce lipid peroxidation, oxidize $\mathrm{Cu}, \mathrm{Zn}-\mathrm{SOD}$, resulting in inactivation of the enzyme. This inactivation of $\mathrm{Cu}, \mathrm{Zn}-\mathrm{SOD}$ by perox$\mathrm{yl}$ radicals could also be involved in the reduction of hepatic $\mathrm{Cu}, \mathrm{Zn}-\mathrm{SOD}$ activity in rats with a single $\mathrm{CCl}_{4}$ treatment, because hepatic lipid peroxidation was enhanced in the liver of $\mathrm{CCl}_{4}$-treated rats, as described above.

In conclusion, the results of the present study indicate that XOD-derived oxygen free radicals contribute to the progression, but not the formation, of $\mathrm{CCl}_{4}$-induced acute liver injury in rats both by stimulating lipid peroxidation and by disrupting the antioxidant defense system through GSH loss and the reduction of the ability of $\mathrm{Cu}, \mathrm{Zn}-\mathrm{SOD}$ to scavenge $\mathrm{O}_{2}{ }^{-}$in the liver tissue. However, further investigation is required to clarify the exact role of $\mathrm{XOD}^{-}$ derived oxygen radicals in the progression of $\mathrm{CCl}_{4}$ induced acute liver injury.

\section{References}

[1] Poli, G.: Liver damage due to free radicals. $\mathrm{Br}$. Med. Bull., 49, 604-620, 1993.

[2] Kaplowitz, N. and Tsukamoto, H.: Oxidative stress and liver disease. Prog. Liver Dis., 14, 131-159, 1996.

[3] Fridovich, I.: Quantitative aspects of the production of superoxide anion radical by milk xanthine oxidase. $J$. Biol. Chem., 41, 4053-4057, 1970.

[4] Porras, A.G., Olson, J., and Plamer, G.: The reaction of xanthine oxidase with oxygen. Kinetics of peroxide and superoxide. J. Biol. Chem., 256, 9096-9103, 1981.

[5] Ramboer, C., Piessens, F., and de Groote, J.: Serum xanthine oxidase and liver disease. Digestion, 7, 183195, 1971.

[6] Giler, S.H., Sperling, O., Brosh, S., Urica, I., and de Vries, A.: Serum xanthine oxidase in jaundice. Clin. Chim. Acta, 63, 37-40, 1975.

[7] McHale, A., Grimes, H., and Coughlan, M.P.: Human serum xanthine oxidase: Fluorometric assay applicable to the investigation of liver diseases. Int. J. Biochem., 10, 317-319, 1979.

[8] Yamamoto, T., Morikawa, Y., Takahashi, S., Tsutsumi, Z., Yamakita, J., Nasako, Y., Hiroishi, K., and Higashino, K.: Determination of human plasma xanthine oxidase activity by high-performance liquid chromatography. J. Chromatogr., B681, 395-400, 1996.

[9] Battelli, M.G., Musiani, S., Valgimigli, M., Gramantieri, L., Tomassoni, F., Bolondi, L., and Stripe, F.: 
Serum xanthine oxidase in human liver disease. Am. J. Gastroenterol., 96, 1194-1199, 2001.

[10] Stripe, F., Ravaioli, M., Battelli, M.G., Musiani, S., and Grazi, G.L.: Xanthine oxidoreductase activity in human liver. Am. J. Gastroenterol., 97, 2079-2085, 2002.

[11] Miyazawa, T., Suzuki, T., Fujimoto, K., and Kaneda, T.: Phospholipid hydroperoxide accumulation in liver of rats intoxicated with carbon tetrachloride and its inhibition by dietary $\alpha$-tocopherol. J. Biochem., 107, 689-693, 1990.

[12] Ohta, Y., Sasaki, E., Nishida, K., Hayashi, T., Nagata, M., and Ishiguro, I.: Preventive effect of Dai-saiko-to (Da-Chai-Hu-Tang) extract on disrupted hepatic active oxygen metabolism in rats with carbon tetrachloride-induced liver injury. Am. J. Chin. Med., 23, 53-64, 1995.

[13] Ohta, Y., Nishida, K., Sasaki, E., Kongo, M., and Ishiguro, I.: Attenuation of disrupted hepatic active oxygen metabolism with the recovery of acute liver injury in rats intoxicated with carbon tetrachloride. Res. Commun. Mol. Pathol. Pharmacol., 95, 191-207, 1997.

[14] Slot, J.W., Geuze, H.J., Freeman, B.A., and Crapo, J.D.: Intracellular localization of the copper-zinc and manganese superoxide dismutases in rat liver parenchymal cells. Lab. Invest., 55, 363-371, 1980.

[15] Ito, T.: Aggrevating effects of changes in defending system against active oxygen species on hepatic injury in rats. Med. J. Kinki Univ. (Kinki Daigaku Igaku Zasshi), 17, 175-190, 1992.

[16] Villela, G.G. and Mitidieri, E.: Rat liver xanthine oxidase in carbon tetrachloride poisoning. Nature, 175, 208-209, 1955.

[17] Affonso, O.R., Mitidieri, E., Ribeiro, L.P., and Villeria, G.G.: Blood serum xanthine oxidase of rats poisoned with carbon tetrachloride. Proc. Soc. Exp. Biol. Med., 90, 527-529, 1955.

[18] Affonso, O.R., Mitidieri, E., and Ribeiro, L.P.: Comparative effects of carbon tetrachloride and colchicines on xanthine dehydrogenase. Experimentia, 23, 291293, 1967.

[19] Candelario-Jalil, E., Monhammed-Al-Falain, S., Fernández, O.S.L., Menéndez, S., Pérez-Davison, G., Merino, N., Sam, S., and Ajamieh, H.H.: Oxidative preconditioning affords protection against carbon tetrachloride-induced glycogen depletion and oxidative stress in rats. J. Appl. Toxicol., 21, 297-301, 2001.

[20] Watts, R.W., Watts, J.E., and Seegmiller, J.E.: Xanthine oxidase activity in human tissues and its inhibition by allopurinol (4-hydroxypyrazolo[3,4-d]pyrimidine). J. Lab. Clin. Med., 66, 688-697, 1965.

[21] Klein, A.S., Joh, J.W., Rangan, U., Wang, D., and Bulkley, G.B.: Allopurinol: Discrimination of antioxidant from enzyme inhibitory activities. Free Radic. Biol. Med., 21, 713-717, 1996.

[22] Irita, K., Sakai, H., Yamakawa, M., Nawata, H., Yoshitake, J., and Takahashi, S.: Effects of OP 2507, a sta- ble analogue of prostaglandin $\mathrm{I}_{2}$, on carbon tetra-chloride-induced liver damage in starved rats. Tohoku J. Exp. Med., 178, 279-285, 1996.

[23] Horváth, T., Karge, E., Jávor, T., and Klinger, W.: Effects of allopurinol, (+)-cyanidanol-3- and dihydroquinoline-type antioxidants on rat hepatic microsomal cytochrome P-450 and monooxygenases. Int. J. Clin. Pharmacol. Ther. Toxicol., 25, 201-203, 1987.

[24] Takahashi, T., Sugimoto, N., Takahata, K., Okamoto, T., and Kishi, T.: Cellular antioxidant defense by a ubiquinol-regenerating system coupled with cytosolic NADPH-dependent ubiquinone reductase: Protective effect against carbon tetrachloride-induced hepatotoxicity. Biol. Pharm. Bull., 19, 1005-1012, 1996.

[25] Engerson, T.D., McKelvey, T.G., Rhyne, D.B., Boggio, E.B., Snyder, S.J., and Jones, H.P.: Conversion of xanthine dehydrogenase to oxidase in ischemic rat tissues. J. Clin. Invest., 79, 1564-1570, 1987.

[26] Majkic-Singh, N., Bogavac, L., Kalimanovska, V., Jelic, Z., and Spasic, S.: Spectrophotometric assay of xanthine oxidase with 2,2'-azino-di (3-ethylbenzthiazoline-6-sulphonate) (ABTS) as chromogen. Clin. Chim. Acta, 162, 29-36, 1987.

[27] Hashimoto, S.: New spectrophotometric assay method of xanthine oxidase in crude tissue homogenate. Anal. Biochem., 62, 426-433, 1974.

[28] Oyanagui, Y.: Reevaluation of assay methods and establishment of kit for superoxide dismutase activity. Anal. Biochem., 142, 290-296, 1984.

[29] Ohkawa, H., Ohishi, N., and Yagi, K.: Assay for lipid peroxides in animal tissues by thiobarbituric acid reaction. Anal. Biochem., 95, 351-358, 1979.

[30] Sedlak, J. and Lindsay, R.H.: Estimation of total, protein-bound, and nonprotein sulfhydryl groups in tissue with Ellman's reagent. Anal. Biochem., 25, 192-205, 1968.

[31] Lowry, O.H., Rosebrough, N.J., Farr, A.L., and Randall, R.J.: Protein measurement with the Folin-phenol reagent. J. Biol. Chem., 193, 265-275, 1951.

[32] Sun, F., Hamagawa, F., Tsutsui, C., Ono, Y., Ogiri, Y., and Kojo, S.: Evaluation of oxidative stress during apoptosis and necrosis caused by carbon tetrachloride in rat liver. Biochim. Biophys., Acta, 1535, 186-191, 2001.

[33] Recnagel, R.O., Glende Jr., E.A., Dolak, J.A., and Waller, R.L.: Mechanisms of carbon tetrachloride toxicity. Pharmacol. Ther., 43, 139-154, 1989.

[34] Rice, A.L., Roberts, R.J., and Plaa, G.L.: The effect of carbon tetrachloride, administered in vivo, on hemodynamics of the isolated perfused rat liver. Toxicol. Appl. Pharmacol., 11, 422-431, 1967.

[35] Nakata, K. and Higuchi, K.: Relationship between circulatory disturbance and histological lesions in the isolated rat liver resulting from carbon tetrachloride poisoning. Microvasc. Res., 1, 379-389, 1969.

[36] McClugage Jr., S.G. and McCuskey, R.S.: "In vivo" microscopic study of the response of the hepatic microvascular system to carbon tetrachloride poison- 
ing. Microvasc. Res., 3, 354-360, 1971.

[37] Kamada, T., Kishida, Y., Sato, N., Meren, H., Tgu, L., and Abe, H.: Hepatic tissue oxygenation during degeneration and regeneration of the liver in rats treated with carbon tetrachloride. Acta Hepatol. Jpn. (Kanzo), 23, 1249-1255, 1982.

[38] Makino, T.: Measurement of hepatic blood flow by the hydrogen gas clearance method. Experimental and clinical observations. J. Nippon Med. School (Nippon Ikadaigaku Zasshi), 57, 137-146, 1990.

[39] Hocher, B., Zart, R., Diekmann, F., Slowinski, T., Thöne-Reinek, C., Lutz, J., and Bauer, C.: Role of the paracrine liver endothelin system in the pathogenesis of $\mathrm{CCl}_{4}$-induced liver injury. Eur. J. Pharmacol., 293, 361-368, 1995.

[40] Hamer, I., Wattiaux, R., and Conick, S.W.-D.: Deleterious effects of xanthine oxidase on rat liver endothelial cells after ischemia/reperfusion. Biochim. Biophys. Acta, 1269, 145-152, 1995.

[41] Kawamoto, S., Inoue, M., Tashiro, S., Morino, Y., and Miyachi, Y.: Inhibition of ischemia and reflow-induced liver injury by an SOD derivative that circulates bound to albumin. Arch. Biochem. Biophys., 277, 160-165, 1990.

[42] Simes, W., Schmidt, H., Müller, M., Henke, W., and Gerber, G.: $\mathrm{H}_{2} \mathrm{O}_{2}$ formation during nucleotide degradation in the hypoxic rat liver: A quantitative approach. Free Radic. Res. Commun., 5, 289-295, 1986.

[43] Layton, M.E., Wood, J.G., Yan, Z.Y., and Forster, J.: Ischemia/reperfusion alters uric acid and ascorbic acid levels in liver. J. Surg. Res., 64, 1-5, 1996.

[44] Matsui, N., Satsuki, I., Morita, Y., Inaizumi, K., Kasajima, K., Kanoh, R., Fukuishi, N., and Akagi, M.: Xanthine oxidase-derived reactive oxygen species activate nuclear factor kapper B during hepatic ischemia in rats. Jpn. J. Pharmacol., 84, 363-366, 2000.

[45] Fernández, G., Villarruel, M.C., de Ferreya, E.C., de Fenos, O.M., and Castro, J.A.: Imipramine prevention of carbon tetrachloride-induced liver necrosis at late states of the intoxication process. J. Appl. Toxicol., 6, 413-418, 1986.

[46] Ross, D., Cotgreave, I., and Modldes, P.: The interaction of reduced glutathione with active oxygen species generated by xanthine-oxidase-catalyzed metabolism of xanthine. Biochim. Biophys. Acta, 841, 278-282, 1985.

[47] Towner, R.A., Rrinke, L.A., Janzen, E.D., and Yamashiro, S.: In vivo magnetic resonance imaging study of Kupffer cell involvement in $\mathrm{CCl}_{4}$-induced hepatotoxicity in rats. Can. J. Physiol. Pharmacol., 72, 441-446, 1994.

[48] Muriel, P., Alba, N., Perez-Alvarez, V.M., Shibayama, M., and Tsutsumi, V.K.: Kupffer cells inhibition prevents hepatic lipid peroxidation and damage induced by carbon tetrachloride. Comp. Biochem. Physiol. Part C, 130, 219-226, 2001.

[49] Das, D.K., Engelman, R.M., Clement, R., Otani, H., Prasad, R., and Rao, P.S.: Role of xanthine oxidase inhibitor as free radical scavenger: A novel mechanism of action of allopurinol and oxypurinol in myocardial salvage. Biochem. Biophys. Res. Commun., 148, 314319, 1987.

[50] Moorhouse, P.C., Grootveld, C., Halliwell, B., Quinlan, G., and Gutteridge, J.M.C.: Allopurinol and oxypurinol are hydroxyl radical scavengers. FEBS Lett., 213, 23-28, 1987.

[51] Bray, R.C., Cickle, S.A., Fieden, E.M., Roberts, P.B., and Rotilio, G.: Reduction and inactivation of superoxide dismutase by hydrogen peroxide. Biochem. $J$., 139, 43-48, 1974.

[52] Kang, J.H., Kim, K.S., Choi, S.Y., Kwon, H.Y., Won, M.H., and Kang, R.C.: Protective effects of carnosine, homocarnosine and anserine against peroxyl radicalmediated $\mathrm{Cu}, \mathrm{Zn}$-superoxide dismutase modification. Biochim. Biophys. Acta, 1570, 89-96, 2002. 